\title{
Conference briefings
}

\section{'Burnout'}

\section{J. P. Watson, General Psychiatry Section}

'Burnout' is concerned with adaptation to occupational demands and opportunities. According to C. Maslach, whose self-report instrument is widely used, three dimensions contribute to the overall 'Burnout' experience: emotional exhaustion (related to overload); depersonalisation (loss of concern for people at work); and reduced or lost job satisfaction. Causes may include problematic relationships at work; organisational factors; and individual characteristics.

These issues were the subject of a Section Conference held at the Royal Society, London on 21 October 1992. The first speaker, Dr Graeme Roberts suggested that, for psychiatrists, the risk of burnout is high. The insidious development of the condition may make it hard to recognise, with tragic results. A GP, Dr Ruth Chambers, next presented data pointing to the high incidence of burnout phenomena among doctors. She had studied GPs but the factors she found to be associated with burnout, such as being on duty at night indefinitely, and being always liable to be found wanting in an emergency, apply to psychiatrists, especially community-orientated ones.

A wide range of stresses may impair psychiatrists' work performance. Dr Stephen Wood contrasted experiences as consultant in inner London and latterly in a rural area; in addition to living circumstances, local patterns of morbidity, levels of resource, expectations of the service, and organisational structures could all contribute to the experience of job (dis)satisfaction.

Dr Margaret Oates outlined the particular problems with which women in medicine and in psychiatry have to cope, and reminded the meeting that women are still under-represented at the senior levels of the medical profession. It would seem that radically new organisational structures and working arrangements are needed to solve these problems.

Dr Terry Spratley pointed to the special personal qualities required to cope with work in the substance misuse field, and Dr Stephen O'Brien described stressful and also protective factors in the working situation of the military psychiatrist. It would seem that selection of 'the man or woman for the job' is rarely made in psychiatry with anything like the care which is the norm in the Armed Services and also in alcoholism services such as described by Spratley.

Clinician approaches were complemented by contributions from management and organisational perspectives. Dr Anton Obholzer expounded the value of consulting to the organisation in alleviating occupational stress. Mr S. Fletcher, a general manager, reminded the meeting that managers may have considerable work stresses themselves, but in some ways took the business of work stress more seriously than doctors sometimes did. He wondered whether, in view of the importance of colleague selection for good working relationships, it was good practice for consultants to be selected in the sloppy way represented by the Advisory Appointments Committee procedure as sometimes observed by him, which he thought contrasted most unfavourably with the multiselection methods applied in senior manager selection.

Dr Roger Bloor spoke as a clinical director of the advantages of combining clinician and management roles in rescuing the potential for burnout among employees. A sense of helplessness and inability to influence anything one cares about in one's work seem to point unequivocally to consultants playing key roles in management. Training implications were noted, and seen to be extremely important.

The proceedings were concluded by Ian AinsworthSmith, who deals with work-related personal, martial, and family breakdown as hospital chaplain and also as psychotherapist. Among important factors with which doctors have to cope, he emphasised the daily exposure to life and death issues which accompanies medical (and nursing) practice, and the need personally to be able to cope with death and grieving.

All those present agreed that the subject matter of burnout was of profound importance for all psychiatrists and should perhaps be explored further in the College, with reference to established consultants and also to the needs of trainees - bearing in mind that the circumstances in which today's trainees will be consultants may well be very different from those experienced hitherto. 